\title{
Posting of Graphical Bills: An Analytical Perception of Environmental Pollutions in Nigerian Cities
}

\author{
Emmanuel Bankole Oladumiye ${ }^{1}$, B. A. Ogunlade ${ }^{2}$, F. Kayode Omole ${ }^{3}$ \\ ${ }^{1}$ Department of Industrial Design, School of Environmental Technology, Federal University of Technology, Akure, Nigeria \\ ${ }^{2}$ Department of Fine and Applied Art, Ladoke Akintola University of Technology, Ogbomoso, Nigeria \\ ${ }^{3}$ Department of Urban and Regional Planning, School of Environmental Technology, Federal University of Technology, \\ Akure, Nigeria \\ Email: eboladumiye@futa.edu.ng, eoladumiye@gmail.com
}

How to cite this paper: Oladumiye, E.B., Ogunlade, B.A. and Omole, F.K. (2017) Posting of Graphical Bills: An Analytical Perception of Environmental Pollutions in Nigerian Cities. Journal of Environmental Protection, 8, 1100-1118. https://doi.org/10.4236/jep.2017.810070

Received: August 7, 2017

Accepted: September 18, 2017

Published: September 21, 2017

Copyright $\odot 2017$ by authors and Scientific Research Publishing Inc. This work is licensed under the Creative Commons Attribution International License (CC BY 4.0).

http://creativecommons.org/licenses/by/4.0/

\section{cc) (i) Open Access}

\begin{abstract}
More than ever before, environmental preservation has been a critical issue for the survival of the world's habitat. An attempt to explore global trends in environmental monitoring using numerous ways based on different techniques is an exercise in the right direction. This is expedient, given the recent overwhelming growing rate of environmental pollution of advertisement graphical bills worldwide. Posting of advertisement graphical bills constitutes one of the biggest threats to man and his environment as it now appears and as we live in an age of growing sensitivity to environmental cleanliness. Pollution of the Nigerian cities through advertisement bills assumes the general term of outdoor advertising ranging from hand-printed signs, posters, painted bulletins and spectaculars. However this paper discusses the trends of posting graphic advertisement bills in Nigerian cities. Its impact on aesthetics, as well as the pollution problems associated with the urban development. The study areas are Abuja, Akure, Ibadan and Lagos. In order to ensure that each unit of the population is represented, random sampling technique was used to get the necessary information from the samples. The findings emphasize the importance of strict control and market regulations in posting of advertisement bill in built environment and eradication of pollution of the environment.
\end{abstract}

\section{Keywords}

Graphical Bills, Pollution, Environmental, Posting, Perception 


\section{Introduction}

The Nigerian built environment has been abused at the expense of technological, political and industrial advances which were considered the ideal and much more described than ecological factors. This philosophy, along with the effect of over population has resulted in the ability of some cities in Nigeria to support life. More polluted air caused by environmental placement of bills at random is being breathed. Even water, both domestic and industrial is being consumed. The mission of environmental health scientist in Nigeria is to perform and promote research to develop the knowledge base needed for preventive programmes for environmental cleanliness especially for posting of advertisement bills in built environment which is a means of great pollutions.

Advertisement is a spinning industry in Nigeria that forms part of everyday culture, often adding colour to the streets, a good indicator of business and valuable source of information viewed by many as a form of entertainment and information. Advertisement can be defined as a form of communication used to persuade an audience to take some action with respect to products, ideas, or services are executed by the use of posters, bills, billboard, and handbills among others, all are graphic design products [1].

Graphic advertisement pollution or outdoor advertisement pollutions are everywhere in Nigerian, even some unpatriotic and selfish Nigerians are suspected to be part of the dumping of toxic wastes in Nigerian built environment and posting of bills, dropping of refuse indiscriminately. This is a confirmation that many Nigerian are nonchalant about environmental cleanliness.

Posting of advertisement bills in built environment is an issue that has negative effects on the life of every member of the community with the consequential effects on the citizenry and Nigerian society at large. The built environment can affect an individual positively or negatively, depending on its friendliness or harshness. The insanitary condition of the Nigerian environment and its possible consequences and squealed environment no doubt, is a breeding place for all vectors of diseases that poses danger to the contemporary society like Nigeria [2]. A similar study points out that man in its environment wishes to live perfectly in good health at all times, but taking care of the environment is nothing to them. As a result, posting of graphics advertisement bills has become a major source of pollution in public places in Urban centres in Nigeria, leading to information over-load and visual over-stimulation which has serious psychological effect on humans and also the wastes generated from the materials used in these advertisements such as paper, vinyl synthetic materials, wood, metal and other new media have constituted negative effects on the built environment and human beings [3].

However, this study focuses on the interaction between man and the potentially toxic or harmful agents of graphics which are bill pollution in his environment. It concentrates on recognizing, identifying and investigating environmental factors that may have deleterious effects and an understanding that me- 
chanisms of action of bill pollution agents have in Nigerian biological environment.

\subsection{The Conceptual Framework of Graphical Bills}

In this study graphic design is seen as the methodology of visual communication, and problem-solving through the use of type, space and images. The field is considered as subset of visual communication and communication design in advertisement of products which make use of bill boards, handbills as well as posters in communication media. Bills are generally a term of outdoor advertising which is an infinite variety, ranging from hand-painted sign gracing a roadside vegetable stand to elaborate displays in 'Time square' [4]. These are categorized into four parts posters, painted bulletins, signs and spectaculars. These also embrace advertisements on trains and buses. Outdoor bills or street graphics design products are concerned with communication along streets and highways; they are usually made with symbols and letters as they show on signs, billboards banners, and store fronts and marquees. Outdoor advertising requires bill posting as an effective way to reach a highly mobile audience that spends a lot of time on the road, for people commuting to and from work or as part of their job. It offers the lowest cost for exposure of any major advertisement medium. It produces a major impact because it is big, colourful and hard to ignore. Advertising is a mirror and shaper of public outlook, social behaviours standards, and a frequent criticism against advertising is that there is too much of it and the products cause pollutions [5] [6].

On the other hand, with the introduction of new communication technologies, the fragmentation and incentive nature of advertising methods are improved, reducing clutter. For example, with the increase of technology device usage, more money is invested in advertising on social media, billboards, posters and handbills. Vandalism, in the form of graffiti, is defined as street markings, offensive and inappropriate messages made without the owner's consent. Graffiti adds to visual clutter in neighbourhoods as it makes a disturbance of view, and the writing is often a bad influence to those of younger age groups. Billboards are other examples of excessive advertising. This form of visual pollution has been alleged as a distraction for drivers, corrupting public taste, boosting the infinite need of consumption and cluttering the land [7] [8].

Built Environment generally, is made up of structures such as: market stalls, shopping malls, hospitals, schools, religious buildings: and infrastructure: roads, dam's parts among others. All these, according to Falade [2], are man's efforts from the Palaeolithic era to carve out habitable, comfortable and healthy surroundings for himself from available materials and resources. From another perspective, the built environment could be seen as a product of a long period of evolution and development being a balance of the natural environment into something beautiful and fulfilling an environment which caters for his total wellbeing spiritually, physically, socially, culturally, economically and psycho- 
logical [9]. In reference to the above scenario, built environment can be referred to as an environment that caters for materials, technologies and encompasses issues such as urban aesthetics, graphics, forest and beautiful flowers.

Nigerian built environment takes after these qualifications, the impact and effects of posting bills in Nigerian built environment is measured in terms of planning, good architecture, cleanliness, street graphics and art. The effect of posting bills on our social environment is impossible to be ignored because posters of all sizes, shapes and kinds were employed to bring to public awareness the merit and the very existence of many products and services. Before long almost every wall is full of posters, this was known as "Bill Sticking". One of the criteria for sticking a bill is finding a good location where it could be seen and this creates defacing of public building. The unfavourable characteristic of posting bills in the environment is the quality that medium lends to the message. The association, in fact, may be a negative one among those people who feel that outdoor advertising clutters and obliterates the natural beauty of the environment [10].

In the study conducted by Ogunduyile [11], Emeji [12] and Oladumiye [3], attention was drawn to the bill pollution in Nigerian built environment, the study criticised the indiscriminate and proliferate of pasting low quality of outdoor posters that inform, and warn. Also it identifies corporate goods and services of medium and, large plus small poster system of individual traders and professionals with little or no consideration for human, psychological and environmental factors, coupled with juxtaposition of incompatible elements cause's visual disorders in built environment. Nigerian built environment has been a conflux of divers things, the individual messages and their untidiness are incomprehensible to the people, for example, weak posters and bills are removed by wind and rain, some are torn into pieces; the peeling of the bills constitute visual environmental pollution. Some of these bills are not replaced for many years, and months, thereby polluting the built environment. They have failed to deliver the message meant for the people due to lack of application of the basic elements of design. They therefore project visual disorder and visual clutter perpetuating visual pollution, visual chaos and visual obstruction which tend to diminish aesthetic sensibility and visual literacy in Nigerian cities. Environmental pollution of bills is assuming global magnitude and its frontiers are no more confined to any particular part of the planet. Nigeria as a country is not left out of this point because they share the biggest intimidation of unkempt built environment [3].

\subsection{Emerging Trend of Posting Bills in Nigerian Built Environment}

The posting of bills in Nigerian built environment came into existence as a result of the advent of graphic signs in 1390s when merchants were required to label their premises, wares and products with signs and identifications. As a result, the 
use of signs gained a wider currency in the $16^{\text {th }}$ century as it was defined as any writing, including letter, pictorial representative, illustrations and decoration, banners, flags or any other figure of similar characteristic. The significance of posting bills came into existence in England in $16^{\text {th }}$ century. Stewart [13], note that merchants were directed to mount their signs on their building surfaces. This brought the idea of house numbering for easy identification which is still in operation till date. People imbibed the idea and developed recognizable emblems as their trademarks

The various studies and experimentation that greeted the industrial revolution of this period brought about the emergence of various mechanical devices to mass produce items formerly made by hand. The moveable type of printing machines which introduced dynamic use of colour fonts and graphic design signs were invented. This gave additional impetus to handbill placements. In the $19^{\text {th }}$ century, other printing techniques, such as screen, lithographic printings add impetus to printing. As a result, the aroused scramble for bill posting spaces thus degenerated to a point that street walls, fence and available spaces were pasted with posters and handbills [14].

Advertisement in Nigeria followed after the pattern of Europe and urban growth in Nigeria took place before the arrival of infrastructural characteristics of industrial cities. Cities like Kano, Jos, Kaduna, Lagos, Ibadan, Port Harcourt and Abuja to mention a few had developed dual urban structures with poorly developed built environment and others with beautiful environmental aesthetics were destroyed with the posting graphical bills indiscriminately. The whole aesthetics of the built environment of these cities were completely destroyed. In 1920s, the first billboard and posters were put in place by West African Publicity Company, United African Company and later Afro media. This advertising company began to profane the use of billboards for highway advertisements. Posting of advertisement bills in banking hall, stadium and all available spaces emerged. Also, after the independence, petty traders eventually grasped the importance of bills and posters which they used to boost their trade. In 1990s, many workers embraced petty trading so as to improve their revenue and as a result, shops and super markets increased on Nigerian streets. Posting of bills were then abused and this led to environmental pollution in the country.

The constantly growing need for advertising products especially outdoors, both for commercial and non-commercial purposes was a surge in new trends and innovations in the different forms of outdoor advertisement to carry out the requirements and targets of practitioners and clients. Constant advertisement of products led to a near-saturation of public places in built environment with posters, billboards, banners, with screaming logos, colours messages and political propaganda to the teeming citizens, not only is these different advertisements media effective in delivering intended messages; they are also sources of growing pollution in the environment. The current trend of posting advertisement bills outdoor in built environment is a major contributor to solid waste and visual 
pollutions in Nigerian built environments [14].

\subsection{Causes of Environmental Pollution of Graphical Bills in Nigerian Built Environment}

Nigeria's current population stands at 170.1 million and is projected to increase to 234.4 million by mid-2025 and to 402.4 million by mid-2050 [15]. As a result of the population, the rates of rural urban drifts and development of built environment are increasing in Nigeria. The population has produced a corresponding increase in the production and importation of consumers, and constantly evolving consumer's retailers in looking for space to advertise their goods and wares. For instance, Nigeria is the largest market for consumer products in Afri$\mathrm{ca}$, as a result, consumers in built environments are constantly being "bushed" with new adverts of new products, which lead to rebranding of products, offer of promo and bonanzas, all of these employing different and new forms of advertising medium to reach out to the ever-growing urban population which cause environmental pollution of advertisement bills.

Advertisement bills are produced in different medium including paper, vinyl, metal sheets and other synthetic materials. They are usually pasted on walls shop doors and glasses, public amenities and even on trees in some cases, they are also given out to the public in the case of flyers, pamphlets, or mounted on different types of structures in varying sizes and shapes, including booths, kiosk, pylons, poles and gantries, buses, taxis and trains are polluted indiscriminately with posting of bills and posters in Nigerian built environment.

Plates 1-3. Indiscriminate posting of bills on Government Properties, Electricity Poles, Bridges and Bus stop in Lagos State Nigeria, Akure and Abuja Nigeria (Authors Collection, 2016).

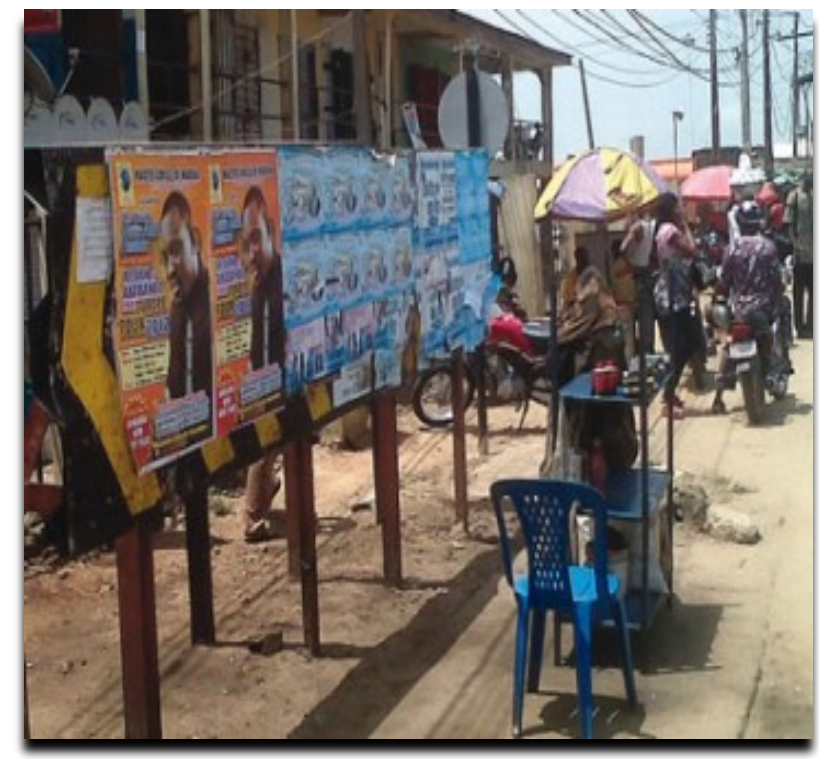

Plate 1. Posters on public bus stop at Akure. Source: Authors collection 2016. 


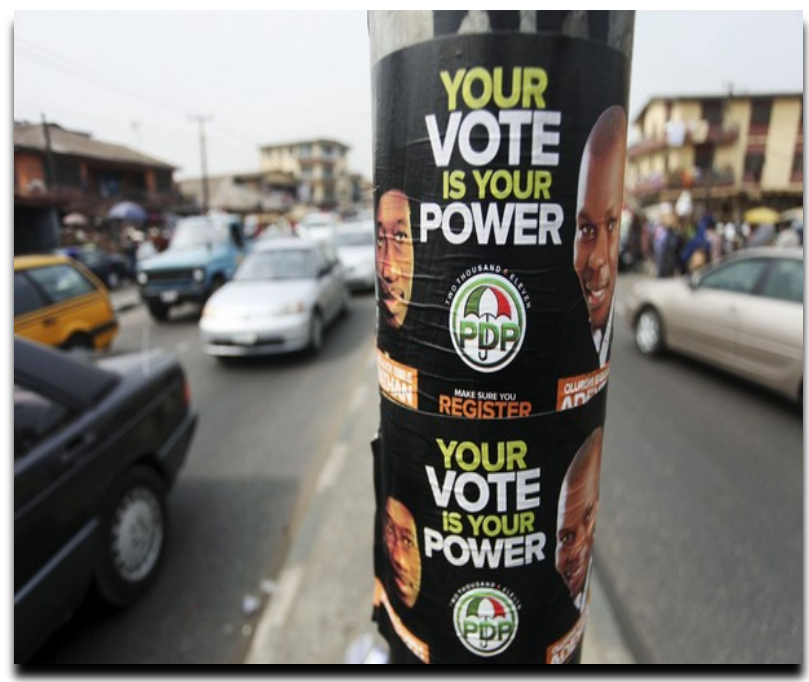

Plate 2. Bills and posters on Electricity Pole. Lagos. Nig, Source: Authors collection 2016.

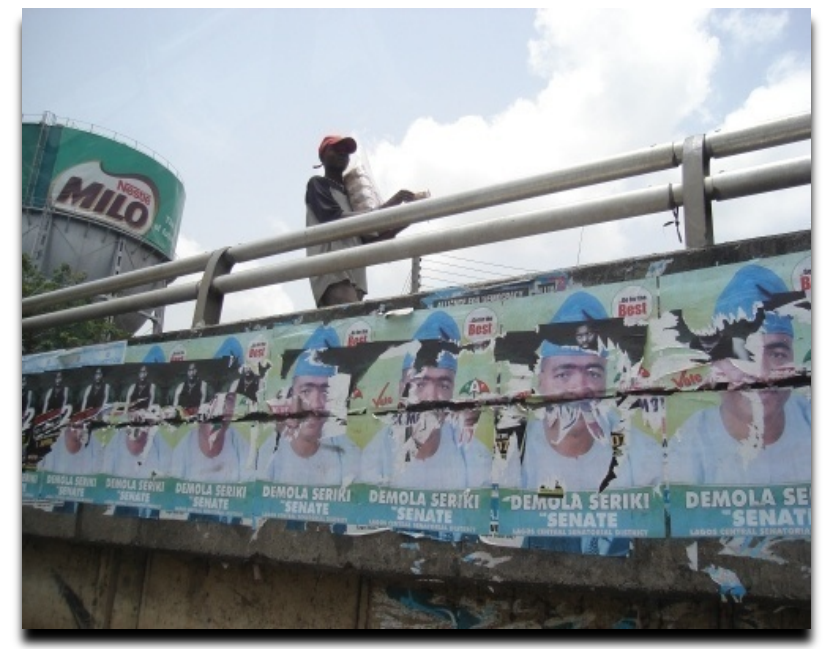

Plate 3. Bills and posters on Bridge Abuja Nigeria. Source: Authors collection 2016.

\subsection{Political Campaign and Social Trends}

Political and social trends in Nigeria caused pollution of the built environment, through posting of advertisement bills indiscriminately. Nigerian politics has become a big consumer of outdoor advertisement bills. Also religious activities have been on a very high increase. Most of the streets in Nigerian cities are constantly being riddled with colourful and glossy posters, flyers, pamphlets of political candidates, religious programmes, social events and meetings. All of these contribute to the environmental pollution of Nigerian built environments. The easiest method for political candidates to get themselves known is to put up posters and advertisement bills featuring their faces and these graphics materials are pasted on all available spaces. Example is Plates 1-3. The whole country especially the political parties, politicians and their campaigners are frantically 
preparing to pollute the environment, in frenzy, the whole landscape both in the rural and urban cities with bills from the sizes of tiny bits of paper to giant bills that stretch from some roof tops down to their basements. Posting of political bills are mostly done by touts and party supporters. As a result, most of the victims whose walls and sign posts have been defaced are afraid to protest for fear of molestation [16] [17].

\section{Methodology}

This section deals with the methodology used in the research work. It describes the various processes, procedures, methods and instrumentals by which data are specified and defined, collected and analysed

\subsection{Study Area}

The areas selected for the study are Abuja, Akure, Ibadan and Lagos. The cities were selected because they are State Capitals and major commercial centres in Nigeria, where the target population could be located. Also many of the country's largest banks financial institutions, industries, wide range of manufactured goods including machinery, motor vehicles, electronic equipment, chemicals textile goods are produced in these cities. Media houses are located in these cities and largest advertisements of products are made both in electronic media, billboards, posters and stadia boards. Posting of graphic design bills indiscriminately is common in these cities.

\subsection{Data Collection Instrument}

In this study, data were collected by means of the structured questionnaire technique. One thousand questionnaires (1000) were randomly distributed at Lagos, Abuja, Ibadan and Akure. The questionnaire was divided into four equal numbers 250 per cities.

\subsection{Data Analysis and Discussions}

Appropriate methods of data analysis were very necessary to be able to accurately process the data collected from field survey, and data analysis, where necessary, as a result descriptive analysis was used to facilitate the ease communicating of the results while, at the same time ensure validity. Based on this assertion, frequency and percentage distribution were used to analyse the background information of the respondents and issues raised in the questionnaire.

\subsection{Sex Distribution of Respondents}

The population from which data for this study was collected comprises of male and female respondents.

Figure 1, shows the frequencies of the gender that responded to the questionnaire. 862 male which are $86.2 \%$ and the female are 138 which are $13.8 \%$. The chart illustrates that the male gender has the higher frequency 
From Figure 2, age group 15 - 24 has $36.9 \%$, age group 25 - 34 has $44.2 \%$, age group 35 - 44 has $9.8 \%$, age group 45 - 54 has $7.0 \%$, and age group 55 - 64 has $1.6 \%$ and age group 65 and above has $1.2 \%$. Figure 2 shows that age group 25 34 has the highest percentage of respondents. It implies that these are the age groups of those who used to past posters and bills indiscriminately.

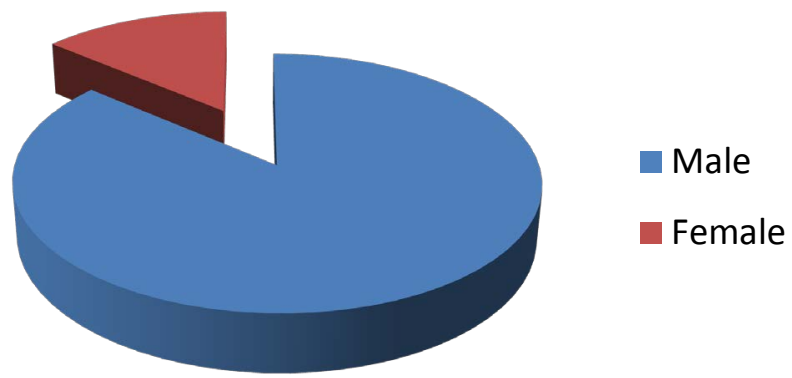

Figure 1. Sex Distribution of the Respondents. Source: Research work 2016.

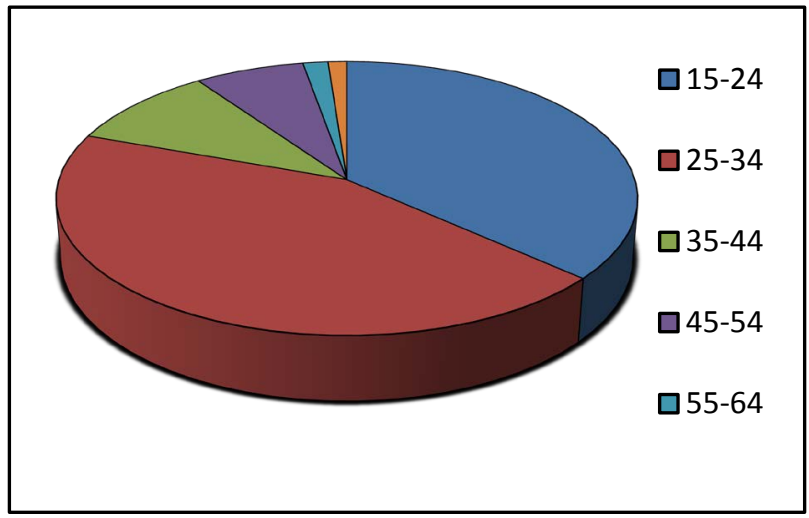

Figure 2. Age Distribution of the Respondents. Source: Research work 2016.

\subsection{Advances in Science and Technology}

Table 1 revealed that $64.0 \%$ of the respondents from Lagos agree that advances in Science \& Technology created environmental pollution of graphic bills while $50.0 \%$ from Akure, $32.0 \%$ from Ibadan also agreed to the point that advances in Technology created environment graphic pollutions and $46.0 \%$ disagree and $32.0 \%$ strongly disagreed in Abuja. Abuja is the capital city of Nigeria. The respondents in the cities were of negative opinion to this point because they believed that advances in Science and Technology is not the major reason for environmental pollution of the Nigerian built environment but lack of regulatory agencies and ineffectiveness of the agencies. The inference in this table is that advances in science and technology have enabled the outdoor spaces to cause environmental pollution of posting bills in built environment. Large format printing machine allows advertisers to produce very large sizes of banners and bills which are pasted at strategic places and left without care. 
Table 1. Advances in Science and Technology have created Environmental pollution through bills in built environmental.

\begin{tabular}{|c|c|c|c|c|}
\hline Location & & & Frequency & Percent \\
\hline \multirow[t]{4}{*}{ Lagos } & Valid & Strongly agree & 30 & 12.0 \\
\hline & & Agree & 160 & 64.0 \\
\hline & & Disagree & 60 & 24.0 \\
\hline & & Total & 250 & 100.0 \\
\hline \multirow[t]{4}{*}{ Akure } & Valid & Strongly agree & 80 & 32.0 \\
\hline & & Agree & 125 & 50.0 \\
\hline & & Strongly disagree & 45 & 18.0 \\
\hline & & Total & 250 & 100.0 \\
\hline \multirow[t]{4}{*}{ Abuja } & Valid & No response & 55 & 22.0 \\
\hline & & Disagree & 115 & 46.0 \\
\hline & & Strongly disagree & 80 & 32.0 \\
\hline & & Total & 250 & 100.0 \\
\hline \multirow[t]{5}{*}{ Ibadan } & Valid & Strongly Agree & 50 & 20.0 \\
\hline & & Agree & 80 & 32.0 \\
\hline & & Disagree & 90 & 36.0 \\
\hline & & Strongly disagree & 30 & 12.0 \\
\hline & & Total & 250 & 100.0 \\
\hline
\end{tabular}

Source: Research work 2016.

In Table 2, most Nigerian cities and towns do not have settlement master plans. There is an observed disorderly mode of occupying usable spaces within Nigerian built environment, some areas where there is some semblance of planning there is a wanton conversion of properties and spaces into different uses that conflict with the law of built environment. The consequences of these problems are that outdoor bills are also posted indiscriminately without any form of restrictions as long as the target audiences are reached. Proper delineation of settlements is lacking in most Nigerian urban centres especially commercial, residential and reserve areas are ridden with posters and bills, people who have appropriated these spaces for their own purposes. As a result, the majority of the respondents from the four cities chosen as the research population strongly agree to this point that lack of major plan is the course of environmental pollution. 64.0\% of the respondents from Lagos 44.0\% from Akure 46.0\% from Abuja and $50.0 \%$ of the respondents from Ibadan strongly agreed to this point and as such it is necessary to have master plans for Nigerian cities to the extent that creation of space for bills will be considered. However some of the states in $\mathrm{Ni}$ geria are trying to create master plan for their cities for instance Abuja the Federal Capital of Nigeria recently embark on demolition of structures built outside the settlement plan of Abuja. 
Table 2. Lack of master plans in Nigerian cities, cause indiscriminate environmental pollution.

\begin{tabular}{|c|c|c|c|c|}
\hline Location & & & Frequency & Percent \\
\hline \multirow{4}{*}{ Lagos } & Valid & Strongly agree & 160 & 64.0 \\
\hline & & Agree & 70 & 28.0 \\
\hline & & Undecided & 20 & 8.0 \\
\hline & & Total & 250 & 100.0 \\
\hline \multirow[t]{4}{*}{ Akure } & Valid & Strongly agree & 110 & 44.0 \\
\hline & & Agree & 80 & 32.0 \\
\hline & & Disagree & 60 & 24.0 \\
\hline & & Total & 250 & 100.0 \\
\hline \multirow[t]{4}{*}{ Abuja } & Valid & Strongly agree & 115 & 46.0 \\
\hline & & Agree & 105 & 42.0 \\
\hline & & Undecided & 30 & 12.0 \\
\hline & & Total & 250 & 100.0 \\
\hline \multirow[t]{5}{*}{ Ibadan } & Valid & Strongly agree & 125 & 50.0 \\
\hline & & Agree & 85 & 34.0 \\
\hline & & Disagree & 25 & 10.0 \\
\hline & & Undecided & 15 & 6.0 \\
\hline & & Total & 250 & 100.0 \\
\hline
\end{tabular}

Source: Research work 2016.

\subsection{Ineffective Regulatory Agencies}

From the result of this study, it is clearly stated and agreed and strongly agreed by the respondents that failure of local governments, are attributed to bills pollution in Nigerian built environment according to Table 3, 72.0\% of the respondents from Lagos agreed to this point and Akure $46.0 \%$ while Abuja $60.0 \%$ and $44.0 \%$ of the respondents from Ibadan strongly agree that the environmental pollution of bills in built environment is caused by ineffective regulatory agencies for instance the placement of bills in Europe and America is usually controlled by regulatory ordinances and legislation. Through their laws, there are factors that allow and monitor placement and posting of bills in their built environment. The local authorities in Nigeria simply enact ordinances regulatory and laws, which reflect the attitude of local community towards posting of graphical bills and signs. In most cases the law provides simple, clear and environment sensitive standard for various types of advertisement bills, but they are not effective. In Nigeria, the local government is mandated by the constitution and decree21 of 1998 to control and collect levies on outdoor advertisement. The local authorities are only interested in the money making aspect of the law leaving the aesthetic planning of Nigerian built environment. Also various decrees have been promulgated by the Nigerian government to set regulatory bodies to 
Table 3. The failure of local government, ministry of environment and monitoring agents are attributed to bills pollution in Nigerian built environment.

\begin{tabular}{ccccc}
\hline Location & & Frequency & Percent \\
\hline Lagos & Valid & Strongly agree & 70 & 28.0 \\
& & Agree & 180 & 72.0 \\
& & Total & 250 & 100.0 \\
Akure & Valid & Strongly agree & 55 & 22.0 \\
& & Agree & 115 & 46.0 \\
& & Disagree & 55 & 22.0 \\
& & Undecided & 25 & 10.0 \\
& & Total & 250 & 100.0 \\
& Valid & Strongly agree & 100 & 40.0 \\
& & Agree & 150 & 60.0 \\
& & Total & 250 & 100.0 \\
& \multirow{3}{*}{ Valid } & Strongly agree & 110 & 44.0 \\
& & Agree & 80 & 32.0 \\
& & Disagree & 20 & 8.0 \\
& & Strongly disagree & 40 & 16.0 \\
& & Total & $\mathbf{2 5 0}$ & 100.0 \\
\hline & & &
\end{tabular}

Source: Research work 2016.

regulate advertising practices in the country. These bodies include: Advertisers Association of Nigeria (ADVAN), Advertising Practitioner Council of Nigeria (APCON) and Outdoor Advertising Association of Nigeria (OAAN). These agencies have formed a monitoring group called the Advertising Standards Panel, (ASP) whose duty is to monitor the posting of graphical bills indiscriminately. There is nothing to indicate that they are really monitoring the practice of bill posting in Nigerian built environments.

\subsection{Environmental Pollutions and the Effects of Posting Bills in Built Environment}

There are several types of environmental pollution and they are from different sources and have different effects and consequences on human health. Pollution can be said to be contamination of the built environment as a result of human activities. The term pollution refers primarily to the fouling of air, water and land by wastes. These sources of pollution simply have a negative impact on the natural world, but they can have a measurable effect on the health of human beings as well. In recent years it has come to signify a wider range of disruptions to environmental quality. Outdoor advertisements now contribute a great deal to pollution in Nigerian built environments mainly as solid wastes and usual pollution [18].

It is a common practice in Nigerian built environment to see advertisement bills posted and mounted at any given place just to catch the attention of the public even in spite of some measures of control in these urban areas. Examples are Plate 4 and Plate 5. These advertisement bills are meant for outdoors they 
have resulting impact and effects on the environment. For instance solid wastes are generated from the materials used in producing these bills, and in built environments, where it is not common to find public spaces cluttered with bills, there is visual pollution. Visual pollution is the form given to unattractive and man-made visual elements of vista, landscape, or any other thing that a person does not feel comfortable looking at. Visual pollution is an aesthetic issue, reflecting to the impacts effect, of bills pollutions that impair one's ability to enjoy a vista or view with undesirable, unattractive views. These may lower the quality of life in certain areas, or it could impact property values and enjoyment. Apart from environmental effects bill posting indiscriminately causes psychological depression and exhaustion and could lead to other health complications. Also, it causes visual pollution which is an aesthetic issue that refers to the impacts of pollution that impair one's ability to enjoy a vista or view. Visual pollution disturbs the visual areas of people by creating negative changes in the natural environment. Billboards, open storage of trash, space debris, telephone towers, electric wires, buildings and automobiles are forms of visual pollution. An overcrowding of an area causes visual pollution. Visual pollution is defined as the whole of irregular formations, which are mostly found in natural and built environment. The greatest effects of exposure to visual pollution include: distraction, eye fatigue, decreases in opinion diversity, and loss of identity.

Table 4 revealed that $20.0 \%$ and $16.0 \%$ strongly agree and agreed and $46.0 \%$

Table 4. Negative effect of posting bills, billboards, posters, handbills on human health.

\begin{tabular}{|c|c|c|c|c|}
\hline Location & & & Frequency & Percent \\
\hline \multirow[t]{6}{*}{ Lagos } & Valid & Strongly agree & 50 & 20.0 \\
\hline & & Agree & 40 & 16.0 \\
\hline & & Disagree & 115 & 46.0 \\
\hline & & Strongly disagree & 25 & 10.0 \\
\hline & & Undecided & 20 & 8.0 \\
\hline & & Total & 250 & 100.0 \\
\hline \multirow[t]{5}{*}{ Akure } & Valid & Strongly agree & 50 & 20.0 \\
\hline & & Agree & 100 & 40.0 \\
\hline & & Disagree & 50 & 20.0 \\
\hline & & Strongly disagree & 50 & 20.0 \\
\hline & & Total & 250 & 100.0 \\
\hline \multirow[t]{5}{*}{ Abuja } & Valid & Strongly agree & 55 & 22.0 \\
\hline & & Agree & 45 & 18.0 \\
\hline & & Strongly disagree & 30 & 12.0 \\
\hline & & Undecided & 120 & 48.0 \\
\hline & & Total & 44 & 100.0 \\
\hline \multirow[t]{4}{*}{ Ibadan } & Valid & Strongly agree & 20 & 8.0 \\
\hline & & Agree & 75 & 30.0 \\
\hline & & Disagree & 155 & 62.0 \\
\hline & & Total & 250 & 100.0 \\
\hline
\end{tabular}

Source: Research work 2016. 


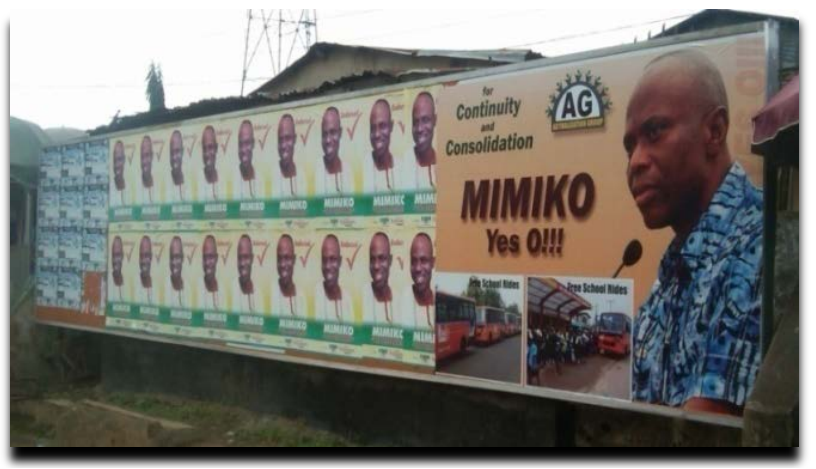

Plate 4. A defaced building with bills. Source: Authors collection 2016.
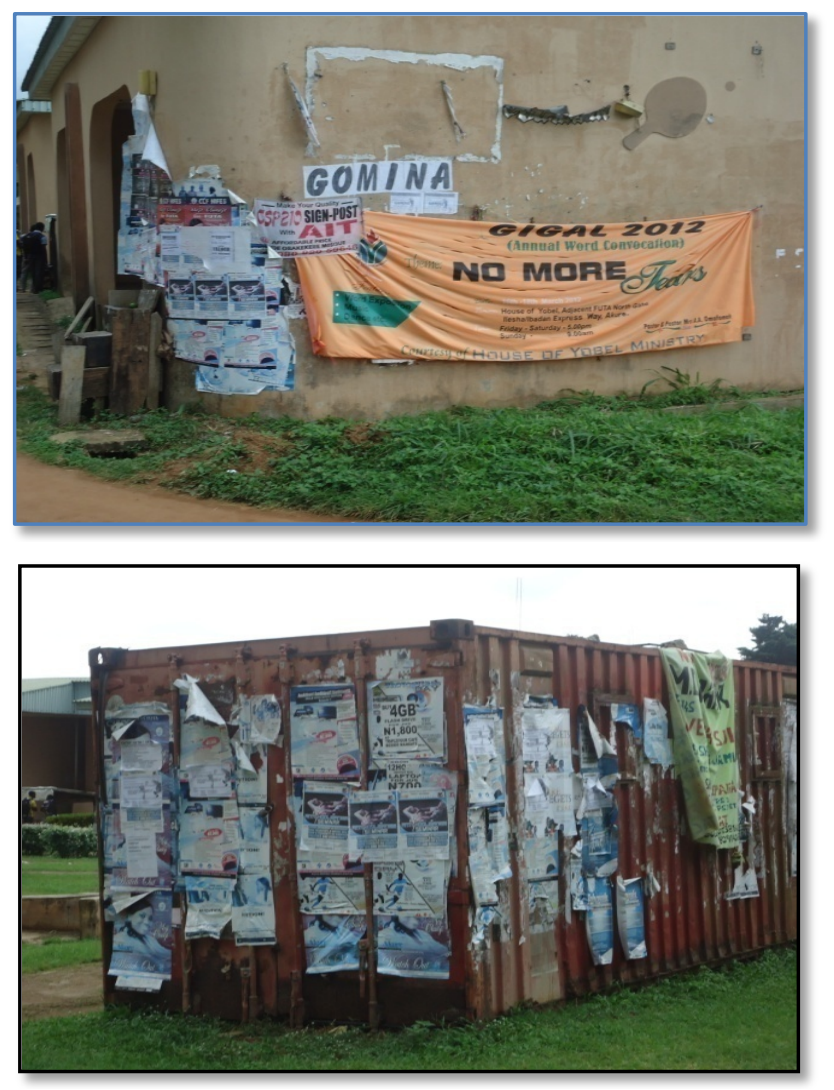

Plate 5. A defaced building and Container with bills. Source: Authors collection 2016.

disagreed to this point while in Akure, $40.0 \%$ agreed and $20.0 \%$ disagreed, in Abuja, $22.0 \%$ strongly agree, $18.0 \%$ agreed and $12.0 \%$ strongly disagreed to this point and in Ibadan $30.0 \%$ of the respondent agreed and $62.0 \%$ disagreed. The inference from this result was that posting of bills, billboards, posters; handbills have negative effect on humans' health environmental values, well-being, and personal health care interdependent. The World Health Organization (WHO) definition of health addresses this interdependence. As the representation of a balanced relationship of the body and mind and complete adjustment to the 


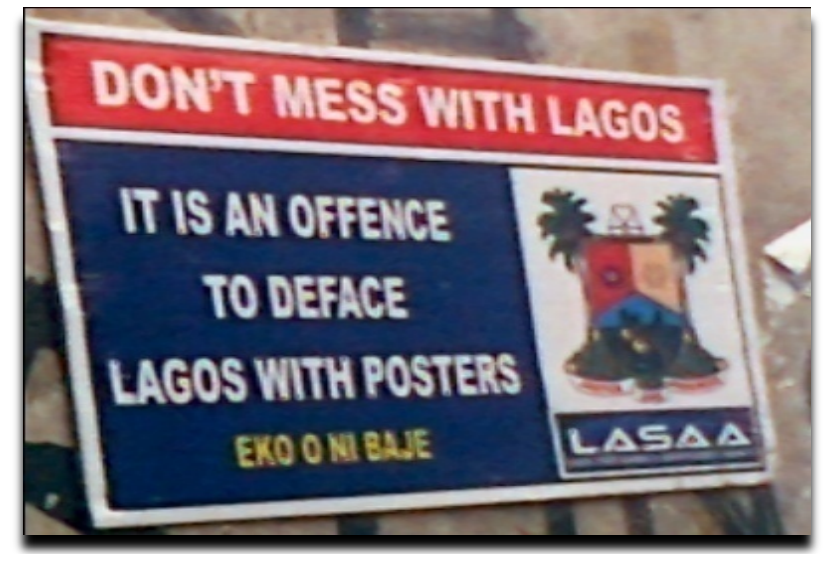

Plate 6. Lasaa bill boards laws. Source: Authors collection 2016.

external environment

Moreover, WHO defines environmental health as comprising those aspects of human health including qualities of life that are determined by chemical, physical, biological, social and psychosocial factors in the environment. It also refers to the theory and practice of assessing, correcting and preventing those factors in the environment that can potentially affect adversely the health of present and future generations. This definition articulates the desire to include elements of quality of life, and psychosocial and sustainable development issues within the sphere of environmental health which are destroy by environmental pollution of graphics bill. Actually good health and well-being require a clean and harmonious environment in which physical, psychological, social and aesthetic factors are all given their due importance [19] [20].

\subsection{Control and Regulation of Bill Posting in Nigerian Built Environment}

Over the years, various decrees have been promulgated by the Nigerian government to set up regulatory bodies to regulate posting of bills in the country because they found it to be of importance to prevent clutter, adequacy control of bills involving illumination and to protect features such as listed building and conservation areas from the potential adverse effects of advertisements. For example, a well-designed and sensitively sited advertisement, where thought has been given to sizes of billboard, colours, sitting and levels of illumination can contribute positively to the visual qualities and environmental harmony of an area. Large number of advertisement bills on a building or along a road can create clutter and be disruptive to the appearance and character of an area. The Nigerian government observed these and promulgated laws to regulate posting of bills in built environment, the law did not work because those in charge did not carry out their work effectively [21].

The beauty and pride of a country is measured in terms of planning good architecture, cleanliness, street graphics, arts and regulating service. These have 
effects on mass communication and social environment. As a result, Nigerian built environment needs regulatory agencies that will enforce advertisement laws and codes especially within the unplanned terrain of Nigerian urban areas. Lagos state has pioneered this by establishing the Lagos State Advertisement and Signage Agency (LASAA). This regulatory agency has helped to bring the outdoor landscape in Lagos to an enviable status. For instance, permission and approval must be obtained before pasting advertisement bills, flyers, pamphlets and hand-outs. Arrangements and payment are made for eventual clean-up within the specific coverage areas of their built environment. Ondo, Osun, Ekiti and Oyo state created similar agencies to check the menace of indiscriminate use of the outdoor spaces. Kano state of Nigeria also hired firm, named Chris Parkes Marketing Services (CPMS) to manage the state's Urban Planning and Development Authority (UPDA) and out spaces. These agencies bring sanity into these cities' built environment.

Also the Sao Paulo, Brazil, the seventh largest city in the world introduced an outright ban on all outdoor advertisement bills and strict control of designated areas for advertisement placements. Lagos, Nigeria, one of the Africa's largest city introduced strict outdoor advertisement laws and it was carried out successfully. In September 2006, according to New York City Global Partners [22] Sao Paulo's populist Mayor, Gilberto Kassab, passed the so-called "CLEAN CITY LAW" outlawing the use of all outdoor advertisements including billboards, transit and in front of stores. The law triggered alarm among city business and other economic constituents. It was reported [23] that critics worried that the advertisement ban would entail a revenue loss of $\$ 133$ million and a net job loss of 20,000 and that the city would look worse without the mask of the media alarmed residents. The law was passed and 15,000 billboards cluttering the world's seventh largest city were pulled down. For almost five years, the country (Sao Paulo) existed without advertisement bills. Instead of economic ruin and deteriorating aesthetics, $70 \%$ of the city residents fined the beneficial according to 2011 survey. The beauty of the city came out. The ban in Sao Paulo reminds the world that it is a city's inhabitants and cultural heritage that bring the true flavour [22] [23] [24].

In 2006, Lagos State House of Assembly passed the State structure for signage and Advertisement Agency Law empowering the Lagos State Signage and Advertisement Agency (LASAA) as the State's outdoor regulating and advertisement control body. Plate 6 (Lassa Bill Board, 2016). The body is to regulate all outdoor bills in the state and also acquire outdoor spaces across the state and advertisement panels, on the BRT system buses and taxi cabs. These spaces are used for commercial and public announcements. All illegal advert bills would be removed and there is a regular clean-up of wastes from building walls, streets, and poles and other public utilities [25].

All advertising agencies were compelled to register before erecting and posting bills in the built environment. Lot of the old fashioned ordinary billboards are 
being removed and replaced with modern technology advertisement outdoor boards. The agency law has transformed the Lagos built environment. An Outdoor Mast Plan was introduced through which outdoor advertisement bills would be used to transform the Lagos State built environment, certain areas are illuminated beyond, using only street lights at night. There is an increasing preference for digital outdoor advertisement bright LED billboards are gradually setting the tone of outdoor advertisement in Lagos, Nigeria [17].

\section{Summary of Findings}

The study revealed that Posting of graphical design bills destroy environmental aesthetics and that the environment is constituted by some simply organics which are being destroyed by the indiscriminate posting of graphical design bills and these have effects on Nigerian built environment. Advances in technology have created environmental pollution. From the study $64 \%$ of the respondents from Lagos agree that advances in Science \& Technology created environmental pollution of graphic bills while 55\% from Akure of the same opinion. While $64 \%$ of the respondents from Lagos $44 \%$ from Akure $45 \%$ While Abuja and Ibadan $43 \%$ of the respondents strongly agreed to this point it is necessary to have master plans for Nigerian cities to the extent that creation of space for bills will be considered. So also it is clearly stated and agreed and strongly agreed by the respondents that failure of local governments are attributed to bills pollution in Nigerian built environment according to the table, $70 \%$ of the respondents from Lagos agreed vividly to this point and Akure $44.4 \%$ while Abuja $56.8 \%$ and $43.6 \%$ of the respondents from Ibadan strongly agree that the environmental pollution of bills in built environment is caused by ineffective regulatory agencies. The results of this study will be useful for the re-planning of Nigerian environment.

\section{Conclusions}

The study has shown that the evolving forms of outdoor advertisement bills are contributing largely to urban pollution. However the unfortunate aspect of the matter in Nigerian built environment is the unpleasant and hazardous conditions to which built environmental advertisement bills are subjected through environmental pollution of advertisement bills, Nigerian street is subjected to an uncared for which is filled with different types of advertisement bills posted indiscriminately at every angle of the city. This study re-emphasizes the high importance of care for Nigerian built environment and considered the importance of the deductions, and that outdoor advertisement which is the major aspect of advertising that makes use of posting of bills in the environment should be effectively regulated and controlled for the benefit of people's health and built environment cleanness. The need to protect and manage our built environment is a major concern of most nations of the world. This is manifested in the numerous legislative measures they put in place to safeguard the environment, such as cre- 
ation of effective laws and semi-autonomous bodies to take care of the built environment. Environmental pollution constitutes the biggest threat to man and his economy as it now appears and as we live in an age of growing sensitivity to environmental cleanliness. Pollution of the environment is due to the activities of man. Based on the aforementioned a clean environment can only be achieved by man's effort to stop polluting his environment e.g. man needs to recognise the forms, structures, identity, and care for the built environment, and attempt to understand the nature of his environment.

For Nigerian built environment to be like Sao Paulo, Brazil. Built Environment codes and conduct should be promulgated into law and it should be followed up by the agencies concerned.

In the cities built environment, regulatory agencies must create free spaces for public notices and information to curb the indiscriminate defacing of public utilities by unregistered advertisers.

There should be check and balance system of regulation to prevent monopolization of outdoor spaces by big advertisers and multinationals.

Other Nigerian states should follow the example of Lagos State and regulate the outdoor advertisement to drastically reduce pollution of the environment

\section{Acknowledgements}

The authors wish to thank Bumi Adeleke for the computation of the research work and the entire search assistants who travelled to the four cities targeted for this research work. We would like to appreciate the staff of Ministry Of Environment Lagos, Akure and Abuja for their contributions towards the completion of this research.

\section{References}

[1] Sinclair, J. (2006) Globalization Trends in Australia's Advertising Industry in Media. International McGraw-Hill, Press Australia, 112, 123, 199.

[2] Falade, J.B. (2005) Globalisation, Cultural and the Nigerian Built Environment. Globalization Culture and the Nigerian Built Environment 2005: Proceeding of the conference on Environmental Design Management O.A.U., Ile-Ife, April 6 2005, $230,237$.

[3] Oladumiye, E.B. (2013) Urban Environmental Graphics: Impact, Problems and Visual Pollution of Signs and Billboards in Nigeria. International Journal of Education and Research, 1, 89.

[4] Wilmshurst, J. (1985) The Fundamentals of Advertisement. Heinemann Ltd., London, 130, 134 .

[5] Robbs, B. (2005) Advertcom Microsoft Encarta Reference Library 2005.

[6] Yilmaz, D. (2013) In the Context of Visual Pollution: Effects to Trabzon City Center Silhoutte. The Asian Social Science Journal, 7, 99.

[7] Robin, P. (2015) Aesthetic Quality of the Built and Natural Environment: Why Does It Matter?

http://artsaccessinternational.org/wp-content/uploads/2012/02/VENICERobinPhili ppwebNational-Environment.pdf 
[8] Morozan, C., Enache E. and Purice, S. (2013) Visual Pollution: A New Axiological Dimension of Marketing? The Journal of the Faculty of Economics-Economic, 1, 820-826.

[9] Osuntogun, A. (2005) The Challenges of Globalisation on the Nigerian Built Environment and Its Culture. Globalization Culture and the Nigerian Built Environment 2005: Proceeding of the Conference on Environmental Design Management O.A.U., Ile-Ife, October16 2005, 340-354.

[10] Makanju, A.A. (2005) Outdoor Advertising: Evolution of Billboards in Lagos Metropolis Issues and Challenges of Creativity in Contemporary Nigerian Art. Journal of Culture and Creative Art Forum, 4, 99-102.

[11] Ogunduyile, S.R. (2000) Urban Aesthetics: Perception and Evaluation of Signs and bill-Board Placement in Nigeria. Journal of Arts and Ideas, 2, 64-68.

[12] Emeji, M.J. (2002) Integrating Visual Arts and Architecture as Instrument of Culture and Symbol System for Enhancing Visual and Aesthetic Environment. Port Harcourt Journal of Nigerian Design History, 6, 20-28.

[13] Stewart, B. (1993) Sign Work. Blackwell Scientific Publication U.S.A, Hoboken, 93-96.

[14] Oladumiye, E.B. (2011) Effect of Graphic Design on Advertisement of Consumer Goods in Lagos Nigeria. Unpublished Ph.D. Thesis, Federal University of Technology, Akure, 89-100, 179-190.

[15] World Population Data Sheet (2012) Population Health and Environment Data and Estimates for Countries and Regions of the World. Population Reference Bureau, New York, 80, 87.

[16] Etsename, L.E. (2007) The Impact of Posting Bills in the Built-Environment. WALE FADARE 2007: Proceeding of towards a Sustainable Built and Natural Environment Conference, O.A.U., Ife, June 5 2007, 435,440,

[17] Adewakun, A. (2011) The Outdoor's Slice of the Election Cake. Punch Newspaper, 19 March 2011.

[18] Fajuyigbe, M.O. (2006) Humanities, Visuals Arts and National Development. $2^{\text {nd }}$ International Conference on Africa: Rethinking Humanities, Ile-Ife, 13-16 June 2006, 27-56.

[19] Howe, G.M. and Lorraine, J.A. (1973) Environmental Medicine. William Heinemann Medical, BKS LTD 23 Bedford Square WE IB. 3HT, London.

[20] World Health Organization (1989) European Charter on Environment and Health. WHO Regional Office for Europe, Geneva, 7.

[21] Njelita, B.O. (2002) Graphic Design in Nigeria: Development Prospects Port Harcourt. Journal of Design History in Nigeria, 1, 48-50.

[22] New York City Global Partners (2012) Best Practice: Clean City Act Innovation Exchange. http://www.nyc.gov/globalpartners/innovationexchange (Accessed 8 September 2017)

[23] Sao Pablo (2012) Five Years after Banning Outdoor Ads, Brazil's Largest City Is More. https://www.newdream.org/resources/sao-paolo-ad-ban (Accessed 8 September 2017)

[24] Shrader-Frechette, K. (1991) Ethics and the Environment. World Health Forum, 12, 311-321.

[25] Lassa Regulation and Rules (2012). Lagos of Nigeria Rules and Regulation on Built Environment Ministry of Environment Lagos Nigeria. 
Submit or recommend next manuscript to SCIRP and we will provide best service for you:

Accepting pre-submission inquiries through Email, Facebook, LinkedIn, Twitter, etc. A wide selection of journals (inclusive of 9 subjects, more than 200 journals)

Providing 24-hour high-quality service

User-friendly online submission system

Fair and swift peer-review system

Efficient typesetting and proofreading procedure

Display of the result of downloads and visits, as well as the number of cited articles Maximum dissemination of your research work

Submit your manuscript at: http://papersubmission.scirp.org/

Or contact jep@scirp.org 